NBER WORKING PAPER SERIES

\title{
ACCOUNTING FOR THE BLACK-WHITE WEALTH GAP: A NONPARAMETRIC APPROACH
}

\author{
Robert Barsky \\ John Bound \\ Kerwin Charles \\ Joe Lupton \\ Working Paper 8466 \\ http://www.nber.org/papers/w8466 \\ NATIONAL BUREAU OF ECONOMIC RESEARCH
1050 Massachusetts Avenue
Cambridge, MA 02138
September 2001
}

We would like to acknowledge helpful comments on a previous draft from Charlie Brown, John DiNardo, Shinichi Sakata, Gary Solon, and Ennio Stacchetti. Financial support was provided by the Michigan Center for the Demography of Aging (P20 AG12846) and the National Institute for Aging (1-R03-AG18392). The views expressed herein are those of the authors and not necessarily those of the National Bureau of Economic Research.

(C) 2001 by Robert Barsky, John Bound, Kerwin Charles and Joe Lupton. All rights reserved. Short sections of text, not to exceed two paragraphs, may be quoted without explicit permission provided that full credit, including (C) notice, is given to the source. 
Accounting for the Black-White Wealth Gap: A Nonparametric Approach

Robert Barsky, John Bound, Kerwin Charles and Joe Lupton

NBER Working Paper No. 8466

September 2001

JEL No. E21, J15

\begin{abstract}
$\underline{\text { ABSTRACT }}$
This paper notes a potential problem in the method of Blinder and Oaxaca - the most popular method in the literature for decomposing the mean difference between groups of a given variable into the portion attributable to differences in the distribution of some explanatory variables and differences in the conditional expectation functions. In its conventional application, the Blinder-Oaxaca method requires that a parametric assumption be made about the form of the conditional expectations function. We show that misspecification is likely to result in non-trivial errors in inference regarding the portion attributable to differences in the distribution of explanatory variables. A nonparametric alternative to the BlinderOaxaca method is proposed. Rather than specify an arbitrary functional form for the conditional expectations function, the method re-weights the empirical distribution of the outcome variable using weights that equalize the empirical distributions of the explanatory variable. Applying this method to the large black-white gap in net worth, we document a substantial difference in the estimated role of earnings differences between the two methods. Our estimates suggest that differences in earnings account for roughly two-thirds of the overall wealth gap.
\end{abstract}

Robert Barsky

Department of Economics

University of Michigan

Ann Arbor, MI 48109-1220

and NBER

barsky@umich.edu

Kerwin Charles

Department of Economics

University of Michigan

Ann Arbor, MI 48109-1220

kcharles@umich.edu
John Bound

Department of Economics

University of Michigan

Ann Arbor, MI 48109-1220

and NBER

jbound@umich.edu

Joseph Lupton

Department of Economics

University of Michigan

Ann Arbor, MI 48109-1220

jlupton@umich.edu 


\section{Introduction}

Though much has been written about earnings differentials between black and white households in the U.S., racial differences in wealth have received far less attention despite the fact that the wealth gap greatly exceeds the earnings gap. Depending on the data used, white households hold five to ten times the net worth of black households (Smith, 1995; Oliver and Shapiro, 1995; Hurst, Luoh, Stafford, 1998; Wolff, 1998, Davern and Fisher, 2001). In contrast, white household income is less than twice black household income (Oliver and Shapiro, 1995; U.S. Bureau of the Census, 1996). Thus it is not surprising that conventional wisdom regards the black-white wealth gap as much too large to be explained by the income gap alone, thereby presenting a separate and perhaps more vexing problem than income inequality.

Recent interest in the racial wealth divide has focused primarily on measuring how much of the gap can be attributed to differences in earnings (Blau and Graham, 1990; Altonji, Doraszelski and Segal, 2000; Altonji and Doraszelski, 2001; Gittleman and Wolff, 2000). The standard approach to answering this question employs a decomposition based on parametric estimation of a wealth-earnings relationship by race. In this paper, we argue that such decompositions are likely to be misleading. The difficulty arises from the fact that the wealth-earnings relationship is nonlinear with an unknown functional form that is difficult to parameterize. As we discuss in section II, if the standard decomposition is to yield valid results, the researcher must do an adequate job of approximating the black and white wealth functions over the relevant range of earnings. In fact, however, attempts at parametric estimation of this relationship are likely to yield inaccurate estimates of the conditional expected wealth functions over significant 
portions of the earnings distribution.

In this paper, we propose a nonparametric alternative to the usual parametric decomposition of the racial wealth difference into the portions explained and unexplained by differences in earnings. Our method in effect re-weights white households in such a way that the earnings distribution of the resultant synthetic white population is approximately coincident to the actual black earnings distribution. The exercise can be interpreted either in terms of a metric for the (weighted) average distance between the black and white wealth functions, or as a simulation of the white wealth distribution under the counterfactual hypothesis that the white population has the black earnings distribution. This method has several advantages. First, because it does not require the estimation of a conditional expected wealth function, it provides a robust alternative to the standard parametric decomposition method, eluding problems of specification error and uncertainty as to functional form. Second, along with a measure of the mean wealth difference conditional on earnings, the re-weighting approach provides an estimate of differences at various points along the entire conditional wealth distribution.

How do our substantive results compare with the results in the existing literature based on the Blinder-Oaxaca method? The key result in the literature is that when the estimated black wealth function is used to simulate both black and white mean wealth, the contribution of earnings to wealth inequality is relatively small - on the order of one fifth. However, when the simulation is carried out on the basis of the estimated white wealth function, earnings account for a much larger fraction - on the order of four fifths (Blau and Graham, 1990; Altonji, Doraszelski and Segal, 2000; Altonji and Doraszelski, 2001; Gittleman and Wolff, 2000). Using data from the Panel Study of Income Dynamics 
(PSID), we show that the parametrically estimated white wealth function underestimates a nonparametrically estimated conditional wealth function for whites in the earnings range relevant for comparison with blacks, thereby overestimating the contribution of earnings to the wealth gap. On the other hand, we show in Section II that there is a fundamental problem with using the black wealth function to estimate black mean wealth given white earnings - it involves projecting the black conditional wealth function into regions of the white income distribution in which blacks are virtually nonexistent. The nonparametric method, which simulates white wealth over the black earnings distribution, provides an answer unaffected by arbitrary specification assumptions. The results suggest that roughly two thirds of the mean difference in wealth between blacks and whites can be explained by differences in earnings. Nevertheless, among the middle-aged, $90 \%$ of black households have less wealth than the median white household even after controlling for the earnings differential.

Section II discusses methods. We first describe the standard parametric method of decomposition and note the problems that arise in its application. We then develop a nonparametric technique that permits an examination of the distribution of an outcome variable, controlling for differences in an explanatory variable, that is independent of functional specification. We also note that this method can easily be extended to the case of multiple explanatory variables. Section III discusses the PSID data the paper uses to examine black-white differences in wealth and earnings distributions. In Section IV, the methods of Section II are applied to show that the mean black-white wealth gap, conditional on earnings, is distorted in a quantitatively important way using parametric methods. This section also presents estimates of the conditional wealth gap at different 
points of the entire distribution of the wealth gap, while controlling for differences in earnings using the nonparametric method. Concluding remarks are offered in Section V.

\section{Methods}

\section{II.A. Blinder-Oaxaca Decomposition}

Consider an outcome variable $W$ for two groups, denoted $a$ and $b$. It is natural to ask how much of the difference between the two groups in the distribution of $W$ is explained by differences in the distribution of an explanatory variable, $Y$. We will identify $W$ with net worth, $Y$ with earnings, group $a$ with whites, and group $b$ with blacks. Throughout this section, we will adopt the convention that capital letters indicate population variables, and lower-case letters indicate a particular value of a variable.

A standard method of assessing the extent to which the wealth gap can be explained by earnings differences is given by Blinder (1973) and Oaxaca (1973). The Blinder-Oaxaca (B-O) decomposition is most often discussed in terms of regressions fitted to sample data. For our purposes, however, it is convenient to begin with a slightly more abstract discussion of the B-O logic, described in terms of conditional expectation functions. This approach does not begin with the any particular presumption about the shape of that the conditional expectation function for wealth given earnings. Further, by focusing explicitly on the distribution of earnings for blacks and for whites, it sets the stage for all of the later analysis.

Denote race as $R \in\{a, b\}$. Let $E[W \mid R, Y]$ be the conditional expected wealth function given race and earnings and $g(Y \mid R)$ the distribution of earnings conditional on race. The expected value of wealth for a given race is then given by 


$$
E[W \mid R]=\int E[W \mid R, y] g[y \mid R] d y .
$$

The B-O decomposition, which focuses on mean differences between groups, is thus implicitly based on (2.1). The method performs the following thought experiment. Imagine integrating the conditional expectation of wealth for whites over the black earnings distribution,

$$
E_{b}[W \mid a] \equiv \int E[W \mid a, y] g(y \mid b) d y .
$$

With this construction in mind, the method decomposes the group difference in mean wealth into the portion attributable to differences in the earnings distribution and the portion attributable to differences in the conditional expectations function. These two components are represented by the first and second terms in the following equality,

$$
\begin{gathered}
E[W \mid a]-E[W \mid b]=\left(E[W \mid a]-E_{b}[W \mid a]\right)+\left(E_{b}[W \mid a]-E[W \mid b]\right) \\
=\int E[W \mid a, y](g(y \mid a)-g(y \mid b)) d y+\int(E[W \mid a, y]-E[W \mid b, y]) g(y \mid b) d y .
\end{gathered}
$$

Note that differences in the earnings distribution are evaluated using the white conditional expectations function. Alternatively, differences in the earnings distributions may be evaluated using the expectations function for blacks, thereby focusing on the quantity

$$
E_{a}[W \mid b] \equiv \int E[W \mid b, y] g(y \mid a) d y
$$

and carrying out the analogous decomposition.

Researchers typically interpret (2.2) and (2.4) in terms of counterfactuals. They regard (2.4) as addressing the question: "what would happen to the mean wealth of blacks if black earnings were to rise to white levels"? Likewise, they see (2.2) as assessing the impact on the mean wealth of whites of a hypothetical downward shift of white earnings to levels characteristic of the black population. This interpretation leads Blau and Graham 
(1990) to the claim that (2.4) is preferable to (2.2) for purposes of forecasting and policy analysis because black earnings are in fact gradually "catching up" to those of the white population, and/or because public policy is devoted to raising the average earnings of blacks.

Because conditional expectation functions are not structural behavioral equations invariant to the distribution of the explanatory variable, the regression parameters are unlikely to remain invariant across policy regimes. It is possible, however, to interpret the decompositions in descriptive terms. In particular, the integral

$$
\int(E[W \mid a, y]-E[W \mid b, y]) g(y \mid b) d y
$$

can be interpreted as a weighted mean distance between the two groups' conditional expectation functions for wealth given earnings, where the weights are based on the black earnings distribution. Similarly, the decomposition based on (2.4) would have an analogous interpretation, with the weights given instead by the white earnings distribution.

Figure 1 illustrates (2.2) and (2.4) graphically. For illustrative purposes, we assume that the earnings distributions are uniform between $A$ and $D$ for blacks and between $A$ and $F$ for whites. The two bold curves, $B C$ and $B^{\prime} C^{\prime} E^{\prime}$, represent hypothetical conditional expected wealth functions for blacks and whites respectively (the dashed curve $C E$ extrapolates the black conditional expected wealth function over the white earnings range). The area enclosed in $A B C D$ divided by the distance $A D$ represents the average wealth of the black population, while the area enclosed in $A B^{\prime} C^{\prime} D$ divided by $A D$ represents the weighted average wealth of the white population, where the weights represent the black distribution of earnings. The area $B B^{\prime} C^{\prime} C$ divided by the distance $A D$ 
represents the weighted average conditional wealth gap. This quantity is the second term in (2.3). Similarly, $B B^{\prime} E^{\prime} E$ divided by $A F$ represents the weighted average conditional wealth gap where the white earnings distribution is used to form the weights.

Note that constructing $B B^{\prime} E^{\prime} E$ requires the extrapolation of the $B C$ curve to $E$. Thus, evaluating (2.2) involves expressions that are observable, whereas evaluating (2.4) involves considerable extrapolation. The figure suggests that using the white earnings distribution will lead to a somewhat larger estimate of the average conditional wealth function. In general, the relative size of the two pieces in the decomposition may differ considerably between the version based on (2.2) and that based on (2.4).

In order to evaluate (2.3), we require an estimate of the conditional expected wealth function.. Typically the researcher approximates this function using a polynomial of fixed order, which we denote as $m\left(Y \mid \theta_{R}\right)$. Define $u(Y \mid R) \equiv E[W \mid R, Y]-m\left(Y \mid \theta_{R}\right)$ to represent the error in the specification of the conditional wealth function. Noting that estimation of the parameters $\theta_{R}$ by least squares insures $E[W \mid R]=\int m\left(y \mid \theta_{R}\right) g(y \mid R) d y$, the B-O decomposition in (2.3) can be rewritten as

$$
\begin{aligned}
E[W \mid a]-E[W \mid b] & =\int m\left(y \mid \theta_{a}\right)(g(y \mid a)-g(y \mid b)) d y \\
& +\int\left(m\left(y \mid \theta_{a}\right)-m\left(y \mid \theta_{b}\right)\right) g(y \mid b) d y
\end{aligned}
$$

Because of specification error, the second term in (2.6) does not necessarily represent differences in the conditional expected wealth function. Although the average specification error in $m\left(Y \mid \theta_{b}\right)$ is eliminated using least squares estimation over the black earnings distribution by construction $\left(\int u(y \mid b) g(y \mid b) d y=0\right)$ it is unlikely that it is eliminated for the white specification over this same range. As a result, the proposed 
counterfactual is likely to be inaccurate, i.e. $\int m\left(y \mid \theta_{a}\right) g(y \mid b) d y \neq E_{b}[W \mid a]$. Depending on the nature of the misspecification, the researcher could either be over- or underestimating the counterfactual of mean white wealth imposing black earnings. The magnitude is an empirical matter, but is likely to be larger the further the projection of the conditional expected wealth function is from the denser portions of the white earnings distribution (White, 1980).

The discussion above demonstrates that because of specification error, the use of parametric techniques to study black-white differences in wealth is likely to lead to inaccurate inferences. Figure 1 makes this point clearer. Here we have fit a linear regression to the hypothetical black and white wealth data. The solid (non-bold) lines represent predicted values from the regression run separately by race. While the slopes of the two conditional expected wealth functions differ, the slopes of the regression lines differ dramatically, particularly over the region $A D$. The reason is simple. The two regression lines represent the best linear prediction of wealth given earnings. For blacks, the fit is maximized over the range $A D$, a region where the actual conditional wealth function is quite flat. In contrast, for whites the fit is maximized over the range $A F$, a range in which the conditional wealth function begins to steepen.

Figure 1 makes clear the consequences of misspecification for the B-O decomposition. Take first the case where the estimated white conditional wealth function is used to simulate white wealth over the $A D$ range of earnings. The estimated line tends to underestimate white wealth over this range. As a result, the $A B^{\prime} C^{\prime} D$ area is underestimated. By contrast, the estimated black conditional wealth function correctly estimates the $A B C D$ area, by definition of the least squares estimator. In this case, 
assuming $m\left(Y \mid \theta_{R}\right)=\alpha_{R}+\beta_{R} Y,(2.6)$ will attribute too much of the wealth gap to differences in income between blacks and white, and too little to the true conditional wealth gap. On the other hand, in the case where one uses the estimated black regression line to simulate black wealth over the white earnings distribution, $A F$, the estimated line tends to underestimate black wealth at higher income levels, and the B-O decomposition will attribute too little of the wealth gap to differences in earnings and too much to differences in the true conditional wealth gap.

Indeed, researchers have typically found large differences in the magnitude of the mean wealth gap attributable to racial differences in earnings depending on whether (2.2) or (2.4) is used in the B-O decomposition. Using a linear specification for $m\left(Y \mid \theta_{R}\right)$ along with data from the National Longitudinal Survey of young men and women, "differences in means explain 73.6 (96.6) percent of the wealth differential for married couples (single heads) when the white coefficients are used, but only about 22 percent when the black ones are employed," according to Blau and Graham (1990, p.330). When they rely on the implementation of the black coefficients with white earnings these researchers conclude that earnings differences explain very little of the racial wealth gap. This result is consistent with Altonji, Doraszelski and Segal, (2000), Altonji and Doraszelski, 2001, and Gittleman and Wolff (2000).

Observations based on Figure 1 suggest that the simplest B-O method approximating conditional expectations by best linear predictors - is likely to be misleading when the true conditional expectation functions are nonlinear. A natural suggestion would be the inclusion in the regression of higher order terms in earnings, 
such as a quadratic, in order to capture the curvature of the true function. But unless the underlying conditional expectation function is truly a quadratic, the estimated functions will tend to under- and over- estimate wealth in different segments of the earnings distribution. When using the estimated white (black) conditional expected wealth function to approximate average white (black) wealth, the errors in specification cancel out. However, as noted above, there is no such presumption if one uses the estimated white (black) function to calculate average wealth with earnings comparable to blacks (whites).

\section{II.B. A Nonparametric Method for Group Comparisons Independent of Functional Specification}

It is possible to avoid making any assumption about the functional form of the conditional expected wealth function in (2.2) by instead noting the relationship between the black and white earnings distribution. By Bayes' rule, $g(Y \mid b)=\omega(Y) g(Y \mid a)$ where the 'weight', $\omega(Y)$, is given by

$$
\omega(Y)=\frac{\operatorname{Prob}(b \mid Y) / \operatorname{Prob}(b)}{\operatorname{Prob}(a \mid Y) / \operatorname{Prob}(a)}
$$

Thus, (2.2) is can be evaluated by

$$
E_{b}[W \mid a]=\int \omega(y) E[W \mid a, y] g(y \mid a) d y
$$

which is simply the weighted expected value of white wealth where the weights reflect differences in the earnings distributions between black and white households.

To evaluate (2.8), we can simply use the empirical white wealth distribution thereby avoiding a functional specification for $E[W \mid a, y]$. This, however, requires an estimate of the weighting function $\omega(Y)$. As is evident, $\omega(Y)$ is a simple transformation 
of the propensity to score function that has received considerable attention in both the statistics and econometrics literature (Rosenbaum and Rubin, 1983, 1985; Heckman, Ichimura and Todd, 1997). The estimator we are proposing involves re-weighting the white wealth distribution using a nonparametric estimate of the propensity to score. In recent work, Hirano, Imbens and Ridder (2000) have shown that nonparametric estimates of the propensity to score lead to fully nonparametrically efficient estimates of the quantity in question.

In fact, the statistic of central interest in this paper (2.5) is formally identical to a parameter that has received a good deal of attention in the program evaluation literature, i.e. the effect of treatment on the treated (Rubin, 1977; Heckman and Robb, 1985; Heckman, Ichimura and Todd, 1997, 1998). However our interpretation of (2.5) is somewhat different. While in the program evaluation literature the focus is on the estimation of the causal effect of a treatment on the population treated, we are interested in the "effect" of being black on wealth holding in the black population. We do not necessarily interpret this "effect" as causal in any meaningful way. At best, the resulting quantity may be interpreted as an estimate of the importance of factors other than income alone that effect racial differences in wealth holdings. At minimum it as a measure of the average conditional (on income) wealth gap between black and white households.

The analysis presented in this paper differs from the literature on using the propensity to score to estimate treatment effects in two other dimensions. First, the literature has focused almost exclusively on estimating mean effects. However, in addition to avoiding a functional specification for the conditional expected wealth function, the re-weighting technique we are proposing also allows the researcher to 
examine the effect of treatment on the entire distribution of outcomes. Using the weighting function (2.7) and focusing on the full white wealth distribution $h(W \mid a)=\int f(W \mid a, y) g(y \mid a) d y$ where $f(W \mid a, Y)$ is the conditional wealth distribution given race and earnings, we can consider the following counterfactual wealth distribution,

$$
\begin{aligned}
h_{b}(W \mid a) & \equiv \int f(W \mid a, y) g(y \mid b) d y \\
& =\int \omega(y) f(W \mid a, y) g(y \mid a) d y
\end{aligned}
$$

where the last equality is simply the white wealth distribution re-weighted in such a way that the earnings distributions of black and white households are coincident. While the BO decomposition focuses on the mean counterfactual, (2.9) expresses the distributional counterfactual.

This technique is similar to the method developed by DiNardo, Fortin and Lemieux (1996) to study the effect of changes in unionization rates on the distribution of wages. DiNardo et al emphasize the value of nonparametric methods for studying the entire distribution of wages. Similarly, the nonparametric approach used here permits investigation of the role of income in accounting for the racial wealth gap at multiple points along the income distribution. But the nonparametric approach can be important even if one is interested only in means: nonparametric techniques allow the researcher to avoid making parametric assumptions that, as we show below, can lead to incorrect inferences.

In section IV, only the white earnings distribution is re-weighted so that it resembles the black distribution. The opposite counterfactual is not examined. The reason is that the empirical conditional expected wealth function for blacks is not observed over 
much of the white earnings distribution. The range of earnings for whites far exceeds that of blacks. This means that there is no feasible nonparametric analogue to the version of Blinder-Oaxaca in which the black regression is used to predict the earnings of hypothetical blacks with high earnings. Because there are relatively few very high earning blacks in the population, and essentially none in our sample, it is not possible to speculate about the wealth-earnings relationship at high levels of earnings without assuming a functional form and extrapolating out of the observed black earnings range. For the reasons discussed above, we do not make these functional form assumptions.

\section{The Data}

We use the Panel Study of Income Dynamics (PSID) to study the black-white wealth gap conditional on earnings. The PSID is a longitudinal survey that tracks the economic and demographic activities of approximately 6,000 households over their life course and spans the years 1968 to the present (Hill, 1992). As of 1994 more than $60 \%$ of the original set of sample household remained in the study. Weights have been constructed to account for differential attrition as well as the initial over-sampling of poor households and the expansion over time in the number of younger households in the sample. Validation studies have documented that analyses of the PSID yield nationally representative results for the non immigrant population when sample weights are applied (Becketti, Gould, Lillard and Welch, 1988; Duncan and Hill, 1989). These sample weights are used in all analyses presented in this paper.

In 1984, 1989 and 1994, the PSID collected detailed information on asset and liability holdings. Quality of these data are enhanced by bracketed random imputation methods. In this paper, we focus on total net worth. This includes net equity in homes and 
non-housing assets which are divided into seven categories: other real estate; vehicles; farm or business; stocks, mutual funds, investment trusts and stocks held in IRAs; checking, savings accounts, CD's, treasury bills, savings bonds and liquid assets in IRA's; bonds, trusts, life insurance and other expensive collections; and other debts.

The sample used in this paper is comprised of black and white headed households in the 1984, 1989 and 1994 PSID. Households heads are required to be present in the survey in at least the five years prior to the 1984, 1989 or 1994 survey year. We restrict the sample to households whose heads are between the ages of 45 and 49. This serves several purposes. First, by restricting to a small age range, differences in the distribution of ages between blacks and whites in the population are rendered irrelevant. Indeed, the mean age of both black and white household head is 47 in the sample. Second, any examination of wealth is better served by focusing on older households since they have had time to accumulate assets. Third, focusing on the racial wealth differences among households older than fifty is confounded by the fact that blacks are more likely to retire earlier than whites. Fourth, because substantial inheritances become more likely among households older than age fifty, measured wealth in the sample will likely not contain inheritances. Inheritances are, of course, a matter of great interest. But, since we wish to study the role that own income plays in generating own wealth, the fact that most of the sample will not have received inheritances as of the time studied means that we can be assured that this variable is less likely to be confounding the relationship of interest. Fifth, and finally, a five year age range is required to avoid a household being represented more than twice in the sample. The final sample size is 1,300 households with 409 black heads and 891 white heads. 
As a proxy for lifetime earnings, we define average labor earnings as the average of household labor earnings over all years the head was head of household in the PSID. Given the restriction above, each household is guaranteed to have at least the five most recent years of labor earnings available. Summary statistics including the mean as well as various percentile points in the distribution for total net worth and average labor earnings are presented in Table 1. Dollar values in this paper have been converted to 1989 constant dollars using the consumer price index for all urban consumers (CPI-U). Mean household labor earnings for blacks is $\$ 21,400$ which is just over one half that of whites. This is a larger earnings gap than that typically found in the literature for individuals, and arises from the fact that marital rates are significantly lower for black households, thereby lowering household earnings relative to white households. Over $70 \%$ of white households and just under $40 \%$ of black households in the sample are married. The earnings gap pales in comparison to the wealth gap. While black households own $\$ 48,400$ in total net worth at the mean, white households own $\$ 263,700$, a ratio of $\$ 0.18$ to the dollar.

Although the ratio of black to white wealth increases as one moves higher in the distribution, the absolute difference remains significant. The median white household has almost as much wealth as a black household at the $90^{\text {th }}$ percentile. The earnings ratio also increases at higher points in the distribution but the $95^{\text {th }}$ percentile for whites is still $50 \%$ larger than that of black households. This indicates the absence of black households over a sizable portion of the white earnings distribution. It is for this reason that we only focus on white households with earnings comparable to that of blacks. 


\section{Results}

In section II, we outlined the pitfalls of parametric methods of decomposition and offered a nonparametric alternative. In this section, these results are applied to the blackwhite wealth gap conditional on earnings in the PSID. The potential failure of parametric methods stemmed from the fact that the errors attributable to misspecification are unlikely to average to zero over the counterfactual earnings distribution. The less similar the earnings distributions, the more likely it is that this problem will arise and hence that inferences are confounded by specification error.

Figure 2 provides kernel density estimates of average labor earnings by race. The estimation procedure uses the Epanechnikov kernel function with the bandwidth, $b$, determined by $b=0.9 n^{-1 / 5} \min (\sigma, q / 1.34)$ where $\sigma$ and $q$ are the respective standard deviation and inter-quartile range of average lifetime earnings and $n$ is the number of observations. This bandwidth is relatively robust to the skewness and kurtosis of unimodal distributions such as the lognormal and $t$ family of distributions and is based on the minimization of the approximate mean integrated squared error of the density estimate (Silverman, 1986, 40-48). The figure is truncated at $\$ 100,000$ for expositional purposes but it is worth noting that the black maximum earnings value is $\$ 98,000$ while the maximum for whites is $\$ 232,000$. Black households are over-represented at the bottom and under-represented at the top of the distribution relative to white households.

Figure 3 is the empirical counterpart to Figure 1. The bold curve represents a semi-parametric estmate of the wealth-earnings relationship for black and white households using the locally weighted scatter plot smoothing (LOWESS) regression technique of Cleveland (1979). The tricube weighting function is used in the procedure 
with bandwidth set to 0.5 as suggested by Cleveland. We consider this to be a good approximation to the conditional expected wealth function by race. The Lowess curves plots represent the curves $B C E$ and $B^{\prime} C^{\prime} E^{\prime}$ ' in Figure 1. From Table 1, the black $10^{\text {th }}$ to $90^{\text {th }}$ percentile earnings range spans $\$ 2,700$ to $\$ 45,100$. Over this range, the LOWESS curve is relatively flat for both blacks and whites. In contrast, the equivalent earnings range for whites spans $\$ 13,900$ to $\$ 64,600$ - a range where the LOWESS curve steepens considerably.

The effect of the disparity in the distributions of earnings is evident in the estimated regression lines in Figure 3. The linear regressions are almost identical to their hypothetical counterparts in Figure 1. Assuming the LOWESS curve is a reasonable approximation to the true conditional expected wealth function, it is clear that estimates of the counterfactuals will grossly underestimate both $E_{a}[W \mid b]$ and $E_{b}[W \mid a]$. As a result, using the white coefficients with mean black earnings will underestimate the true conditional wealth gap, while the complementary counterfactual will overestimate it.

As noted in section II.A, the addition of a quadratic in earnings is unlikely to capture adequately the nature of the nonlinearity in the conditional expected wealth function. The quadratic curve in Figure 3 (estimated by least squares ) shows considerable deviations from the LOWESS curve, albeit less than the linear regression line. Once again, the parametric procedure will underestimate the counterfactual conditional expectations, and hence either attribute too little or too much of the wealth gap to differences in the conditional expected wealth function, depending on whether one uses the white or black equation, respectively. 
What about higher order polynomials? Certainly, there is no guarantee that a particular low order polynomial - a cubic or quartic, say - would do significantly better at fitting the white conditional wealth function in the relevant range than does the quadratic. Furthermore, standard diagnostic statistics such as the mean square error are not the appropriate criteria for evaluating how well the estimated function approximates (2.5). Our re-weighting procedure provides a simple and intuitive alternative.

To implement (2.7) we need to re-weight the white data in such a way that white households that have earnings similar to those of blacks receive larger weights than those that have earnings unlike those of blacks. A number of both parametric (Rosenbaum, 1987) and nonparametric methods for doing this have been suggested in the literature (Heckman, Ichimura and Todd, 1998; Hirano, Imbens and Ridder, 2000). We present results based on a very simple scheme. We have experimented with other nonparametric alternatives and found that they give similar results. Empirically, given $N_{b}$ black households, white households within a given percentile range of the black average earnings distribution receive a weight unique to that range. This weight is defined as

$$
\varpi(q)=\frac{\alpha}{p(q)} \quad q=1,2, \ldots, \alpha^{-1}, \alpha^{-1} \in\left[1,2, \ldots, N_{b}\right]
$$

where $\alpha$ is the bin size of the chosen percentile range and $p(q)$ is the fraction of white households in the $q^{\text {th }}$ " $100 \alpha$ percentile range" of black average lifetime earnings. In this paper, $\alpha$ is set to 0.05 thereby matching the white average earnings distribution to the black distribution up to the five percentile range. For example, 2.5 percent of white households in the sample are in the third black five percentile range. These white households are given a weight of $\varpi(3)=.05 / .025=2$. Note that any white households 
that fall above the maximum earnings of the black distribution receive a weight of zero. Assuming that the bin size $\alpha$ decreases to zero as the sample size increases, (4.1) is a fully nonparametric estimate of the propensity to score.

The application of these weights to the kernel estimation of the white earnings density is seen in Figure 2. Clearly, the weights perform well in matching the black distribution. Any differences are a result of the width of the re-weighting range. Finer stratification, such as by percentiles of the explanatory variables, does not work very well, particularly in a multivariate context where cell numbers increase dramatically. In this case, one could use either parametric (e.g. DiNardo, Fortin and Lemieux, 1996) or nonparametric (e.g. Heckman, Ichimura and Todd, 1997) methods to estimate the probability that a sample member was black conditional on the characteristics of the sample member and then use this propensity score to construct the weights.

In Table 2, mean net worth is reported by conditional expected wealth function and the earnings distribution imposed on this function. The conditional expected wealth function is estimated parametrically by race using least squares on both a linear and quadratic earnings specification. Both methods of estimation yield the sample mean of net worth when the conditional expected wealth function for a given race is simulated over that group's own earnings distribution. The unconditional wealth gap is $\$ 263,700$ $\$ 48,400=\$ 215,300$. Using either the linear or quadratic specification, imposing the white earnings distribution on the estimated black function indicates that roughly $20 \%$ of the gap is explained by earnings differences. On the other hand, using the estimated linear specification of the white conditional expected wealth function over the black earnings distribution suggests that almost all the gap is explained by earnings differences. Slightly 
less then three fourths of the gap is attributed to earnings differences when the quadratic specification is used. These results are consistent with the literature previously cited.

Nonparametric estimates of mean net worth are also reported in Table 2. These require no functional specification for conditional expected wealth. As in the parametric case, estimates imposing a given race's earnings distribution on its own conditional expected wealth function yield the sample mean. However, the counterfactual of imposing the black earnings distribution on the white conditional expectations function is performed by computing the weighted mean of white net worth, where the weights are defined in (4.1). In this case, white wealth drops by almost one half to $\$ 125,900$. This suggests that $64 \%$ of the gap in mean net worth is explained by differences in the earnings distribution, eaving a conditional mean wealth gap of $\$ 77,500$. As noted in section II.B, nonparametric methods cannot yield a complementary counterfactual, since there are no black households in the upper portion of the white earnings distribution - a point driven home by the black LOWESS curve in Figure 3.

Typically, when calculating standard errors for Blinder-Oaxaca decompositions, researchers condition on the distribution of the explanatory variables in their samples. Were we to take this approach, the calculation of the standard errors for our nonparametric estimate would simply amount to calculating the standard error of a weighted mean. However, in our case, conditioning on the black and white income distribution in our samples seems inappropriate. We want to know the extent to which income differences account for wealth differences in the population, not in this sample.

Rather than assume that the explanatory variables are fixed in repeated samples and use the conventional estimates of the variance of the predicted means, we use the 
complex survey design of the PSID to produce standard errors based on a nonparametric balanced half-sample replication procedure. This method repeatedly estimates the parameters of interest - either parametrically or nonparametrically - over a series of strategically chosen half-samples (Wolters, 1985, Chapter 3). The observed variance of the estimates in each of the half-samples is then used to infer the variance of the estimate in the full sample. Results are reported in parenthesis in Table 2.

Since mean net worth is identical across parametric and nonparametric estimates when imposing the black (white) earnings distribution on the black (white) conditional wealth function, the estimated standard errors are the same across methodologies. The standard error for the mean of net worth is $\$ 7,500$ for black households and $\$ 29,200$ for white households - approximately 0.15 and 0.11 times their respective estimated means. When the black earnings distribution is imposed on the white conditional wealth function, the standard errors vary dramatically depending on which estimated conditional wealth function is used. The linear parametric model produces the largest relative standard error - approximately 0.50 times the estimated mean. Not surprisingly, adding a quadratic term to the model greatly reduces the relative standard error to 0.22 times the estimated mean. However, the lowest relative standard error - approximately 0.13 times the estimated mean- is produced by the nonparametric method. It is worth noting that had we assumed earnings were fixed in repeated samples, the estimated standard errors for the parametric models would be smaller. However, although we do not report them here, the standard errors of the nonparametric estimates are still relatively smaller than those of the parametric estimates. 
We have noted that a major advantage of the nonparametric specification is that one need not stop at the mean; the role of earnings in explaining the racial wealth gap at multiple points in the distribution can be readily assessed. Figure 4 shows the effect of imposing the black earnings distribution on white wealth across the entire distribution. The effect of earnings differences is largest at the bottom of the wealth distribution, decreasing monotonically as we move up the distribution. While $100 \%$ of the gap is attributed to earnings differences at the $10^{\text {th }}$ percentile of wealth and $79 \%$ is attributed at the $25^{\text {th }}$ percentile, this amount falls to $67 \%$ at the median and $63 \%$ at the $75^{\text {th }}$ percentile. At the $90^{\text {th }}$ percentile of wealth, only $55 \%$ of the gap is attributed to earnings differences.

The way in which these conditional distributional differences manifest themselves in terms of the wealth inequality between black and white households is presented in Table 3. The table shows the share of all blacks that fall below a particular percentile position in the white distribution. The basic pattern for earnings, depicted in the first column, has already been discussed. The distribution of white earnings is shifted dramatically to the right for whites relative to blacks. The level of earnings that characterizes the 10th percentile of the white distribution would, if held by a black household, place that household at the $38^{\text {th }}$ percentile of the black earnings distribution. The level of earnings that places a black household at the 90th percentile of the black earnings distribution locates a white household at only the $75^{\text {th }}$ percentile of the white distribution.

The racial disparity in wealth is even more profound than is true for earnings, though the table reveals that it derives more from differences at the top of the distribution. The wealth held by a black at about the $12^{\text {th }}$ percentile of the black wealth distribution is 
identical to that held by a white at the $10^{\text {th }}$ percentile of the white wealth distribution. However, the wealth held by a white at the $25^{\text {th }}$ percentile of the white distribution places a black household at the $78^{\text {th }}$ percentile of the black distribution. The median white household (in terms of wealth holding) has more wealth than any black household.

The final column may be read as summarizing the effect of earnings differences in explaining the racial wealth gap according to the nonparametric technique presented above. The benefit of presenting the results in this way is that the effect of earnings on the racial wealth gap may be assessed at different points in the wealth distribution. The results indicate that differences in earnings account for all of the racial wealth difference in the first quartile of the wealth distribution. However, the role of labor earnings in explaining the wealth gap diminishes quickly as we move up the wealth distribution. Roughly three quarters of black households still lie below the $40^{\text {th }}$ percentile of the reweighted white wealth distribution.

\section{Conclusion}

In this paper we have noted a potential problem in decomposition methods such as Blinder (1973) and Oaxaca (1973) that attempt to decompose the mean difference in an outcome variable into the portion explained by distributional differences in some explanatory variable and the portion explained by a disparity in the conditional expectations functions A problem arises when parametric methods are used to approximate the true conditional expectations function and project it into regions where errors in specification are not likely to average to zero. This paper suggests a nonparametric alternative. Rather than specify an arbitrary functional form for the conditional expectations function, this method simply re-weights the empirical 
distribution of the outcome variable using weights that equalize the empirical distributions of the explanatory variable.

These methods were applied to the black-white wealth gap. Noting a large disparity in net worth between black and white households, it is natural to ask how much of this gap is attributable to differences in earnings. Blinder-Oaxaca results typical in the literature were replicated. They suggest that roughly $20 \%$ of the mean wealth gap is explained by earnings differences using the parametrically estimated black conditional expectations function, while (depending on functional form) somewhere between $72 \%$ and $97 \%$ of the gap can be explained using the estimated white function. Nonparametrically imposing the black earnings distribution on the white conditional expectations function places the mean amount attributable to earnings differences at $64 \%$. No complementary counterfactual is available, since this would involve extrapolating an unknown functional form over earnings where no blacks are present. The role of earnings differences in explaining the wealth gap is largest at the lower tail of the wealth distribution. This role decreases dramatically at higher wealth levels, and is nonexistent by the $60^{\text {th }}$ percentile of the white wealth distribution. 


\section{Reference List}

Altonji, J. G., and Doraszelski, U. (2001), "The Role of Permanent Income and Demographics in Black/White Differences in Wealth. "Mimeo, Northwestern University.

Altonji, J. G., Doraszelski, U, and Segal, L. (2000), "Black/White Differences in Wealth." Federal Reserve Bank of Chicago Economics Perspectives, 24 (1), 38-50.

Becketti, S., Gould, W., Lillard, L., and Welch, F. (1988), "The PSID after Fourteen Years: an Evaluation." Journal of Labor Economics, 6 (4), 472-492.

Blau, F. D., and Graham, J. W. (1990), "Black-White Differences in Wealth and Asset Composition." Quarterly Journal of Economics, 105 (2), 321-339.

Blinder, Alan S. (1973), "Wage Discrimination: Reduced Form and Structural Estimates." Journal of Human Resources, 8 (4), 436-455.

Cleveland, W. S. (1979), "Robust Locally Weighted Regression and Smoothing Scatterplots." Journal of the American Statistical Association, 74 (368), 829-836.

Davern, M., E., and Fisher, P. J. (2001), Household Net Worth and Asset Ownership, U.S Census Bureau, Current Population Reports, Household Economic Studies - Series P7071. Washington, D.C. 20222.

DiNardo, J., Fortin, N. M., and Lemieux, T. (1996),"Labor Market Institutions and the Distribution of Wages: 1973-1993, A Semi-Parametric Approach." Econometrica, 64 (5), 1001-1044.

Duncan, G. J., and Hill, D. H. (1989), "Assessing the Quality of Household Panel Survey Data: The Case of the PSID." Journal of Business and Economic Statistics, 7 (4), 441451.

Gittleman, M., and Wolff, E. N. (2000), "Racial Wealth Disparities: Is the Gap Closing?" Jerome Levy Institute Working Paper Series, 311.

Heckman, J. J., Ichimura, H., and Todd, P. E. (1997), "Matching as an Econometric Evaluation Estimator: Evidence from Evaluating a Job Training Program." The Review of Economic Studies, 64 (4), 605-654.

Heckman, J. J., Ichimura, H., and Todd, P. E. (1998), "Matching as an Econometric Evaluation Estimator." The Review of Economic Studies, 65, 261-294.

Heckman, J. J., and Robb, R. (1985), "Alternative Methods for Evaluation the Impact of Interventions" by Heckman, J. J., and Singer, B., Longitudinal Analysis of Labor Market Data, New York: Cambridge University Press.

Hill, M. S. (1992), The Panel Study of Income Dynamics: A User's Guide. Newbury 
Park, California: Sage Publications, Inc.

Hurst, E., Luoh, M. C., and Stafford, F. P. (1998), "The Wealth Dynamics of American Families." Brookings Papers on Economic Activity, 1, 267-337.

Oaxaca, R. (1973), "Male-Female Differentials in Urban Labor Markets." International Economic Review, 14, 693-709.

Oliver, M. L.,| and Shapiro, T. M. (1997), Black Wealth / White Wealth: A New Perspective on Racial Inequality. New York, NY: Routledge.

Rosenbaum, P. R. (1987), "Model-Based Direct Adjustment." Journal of the American Statistical Association, 82 (398), 387-394.

Rosenbaum, P. R., and Rubin, D. B. (1983), "The Central Role of the Propensity Score in Observational Studies for Causal Effects." Biometrika, 70 (1), 41-55.

Rosenbaum, P. R., and Rubin, D. B. (1984), "Reducing Bias in Observational Studies Using Subclassification on the Propensity Score." Journal of the American Statistical Association, 79 (387), 516-524.

Rubin, D. B. (1977), "Assignment to Treatment Group on the Basis of a Covariate" Journal of Educational Statistics, 2, 1-26.

Smith, J. P. (1995), "Racial and Ethnic Differences in Wealth in the Health and Retirement Study." Journal of Human Resources, 30, Supplement S158-S183.

U.S. Bureau of the Census. (1996), Money Income in the United States: 1995. Current Population Reports, Series P60-193, Washington, D.C. 20222, U.S. Government Printing Office.

White, H. (1980), "Using Least Squares to Approximate Unknown Regression Functions." International Economic Review, 21 (1), 149-169.

Wolff, E. N. (1998), "Recent Trends in the Size Distribution of Household Wealth." Journal of Economic Perspectives, 12 (3), 131-150. 
Table 1: Sample Distribution Properties (Thousands of 1989 dollars)

\begin{tabular}{|l|c|c|c|c|c|c|}
\hline \multirow{2}{*}{} & \multicolumn{3}{|c|}{ Total Net Worth } & \multicolumn{3}{c|}{ Average Labor Earnings } \\
\cline { 2 - 7 } & Black & White & Ratio & Black & White & Ratio \\
\hline Mean & 48.4 & 263.7 & 0.18 & 21.4 & 38.5 & 0.56 \\
Percentiles & & & & & & \\
10th & -3.0 & 0.0 & -- & 0.0 & 7.1 & 0.00 \\
25th & 0.0 & 3.5 & 0.00 & 2.7 & 13.9 & 0.19 \\
50th & 1.4 & 35.0 & 0.04 & 9.4 & 23.1 & 0.41 \\
75th & 18.4 & 110.6 & 0.17 & 16.5 & 36.2 & 0.46 \\
90th & 51.4 & 255.4 & 0.20 & 32.6 & 50.1 & 0.65 \\
95th & 140.8 & 520.8 & 0.27 & 45.1 & 64.6 & 0.70 \\
\end{tabular}

Note:

[1] Table based on authors' calculations using the Panel Study of Income Dynamics. Sample is comprised of black and white household heads in 1984, 1989 or 1994 aged 45 to 49 . Households were also required to have at least five years of observations prior to 1984, 1989 or 1994 (1,300 observations; 409 black and 891 white). PSID sample weights are used in all computations.

Table 2: Mean Net Worth (Thousands of 1989 dollars)

\begin{tabular}{|c|c|c|c|}
\hline & \multicolumn{2}{|c|}{ Imposing the earnings of. } & \multirow{2}{*}{$\begin{array}{c}\text { Percent of Gap Explained } \\
\text { by Earnings }\end{array}$} \\
\hline & blacks & ...whites & \\
\hline \multicolumn{4}{|l|}{$\begin{array}{l}\text { Black Conditional Wealth Function } \\
\text { Parametric }\end{array}$} \\
\hline LSE (Linear) & $\begin{array}{l}48.4 \\
(7.5)\end{array}$ & $\begin{array}{l}91.1 \\
(17.4)\end{array}$ & $19.8 \%$ \\
\hline LSE (Quadratic) & $\begin{array}{l}48.4 \\
(7.5)\end{array}$ & $\begin{array}{l}97.6 \\
(21.7)\end{array}$ & $22.9 \%$ \\
\hline Nonparametric & & & \\
\hline Propensity Score Weighting & $\begin{array}{l}48.4 \\
(7.5)\end{array}$ & -- & -- \\
\hline $\begin{array}{l}\text { White Conditional Wealth Functi } \\
\text { Parametric }\end{array}$ & & & \\
\hline LSE (Linear) & $\begin{array}{l}53.8 \\
(27.1)\end{array}$ & $\begin{array}{l}263.7 \\
(29.2)\end{array}$ & $97.5 \%$ \\
\hline LSE (Quadratic) & $\begin{array}{l}108.5 \\
(23.5)\end{array}$ & $\begin{array}{l}263.7 \\
(29.2)\end{array}$ & $72.1 \%$ \\
\hline$\underline{\text { Nonparametric }}$ & & & \\
\hline Propensity Score Weighting & $\begin{array}{l}125.9 \\
(15.8)\end{array}$ & $\begin{array}{l}263.7 \\
(29.2)\end{array}$ & $64.0 \%$ \\
\hline
\end{tabular}

\section{Note:}

[1] Table based on authors' calculations using the Panel Study of Income Dynamics. Sample is comprised of black and white household heads in 1984, 1989 or 1994 aged 45 to 49 . Households were also required to have at least five years of observations prior to 1984,1989 or 1994 (1,300 observations; 409 black and 891 white). PSID sample weights are used in all computations.

[2] Predicted net worth values for the parametric least squares estimated (LSE) models are based on the the estimated model and mean earnings of either blacks or whites. The mean of these predicted values are reported. Sample weights are used in estimating the model and in computing the mean. Standard errors are in parentheses and computed by balanced half-sample replication.

[3] The nonparametric estimate of the conditional wealth function for whites imposing the mean earnings of blacks is computed as the weighted sample mean of white wealth where the weights are computed so as to match the white earnings distribution to the black distribution.

[4] The non-parametric estimate of wealth for the black conditional wealth function using white mean earnings is not feasible since few black households are present in the top portion of the white earnings distribution.

[5] The gap is defined as the actual mean difference in wealth, $\$ 263,700-\$ 48,400=\$ 215,200$. The counterfactual gap is the difference between 1 ) actual white mean wealth and mean wealth using the black conditional wealth function with white mean earnings or 2) mean wealth using the white conditional wealth function with black mean earnings and actual black mean wealth. The percent explained is one less the ratio of the counterfactual to the actual gap. 
Table 3: Percent of Blacks Below Given Percentile of Whites

\begin{tabular}{|c|c|c|c|}
\hline $\begin{array}{c}\text { White } \\
\text { Percentile }\end{array}$ & $\begin{array}{c}\text { Average Labor } \\
\text { Earnings }\end{array}$ & Wealth & $\begin{array}{c}\text { Wealth } \\
\text { Re-Weighted }\end{array}$ \\
\hline 10 & 38.4 & 12.4 & 5.5 \\
25 & 61.4 & 78.0 & 23.4 \\
40 & 74.3 & 99.6 & 73.3 \\
50 & 78.7 & 100.0 & 90.7 \\
60 & 86.8 & 100.0 & 99.6 \\
75 & 94.6 & 100.0 & 100.0 \\
90 & 98.3 & 100.0 & 100.0 \\
\hline
\end{tabular}

Note:

[1] Table based on authors' calculations using the Panel Study of Income Dynamics. Sample is comprised of black and white household heads in 1984, 1989 or 1994 aged 45 to 49. Households were also required to have at least five years of observations prior to 1984,1989 or 1994 (1,300 observations; 409 black and 891 white). PSID sample weights are used in all computations.

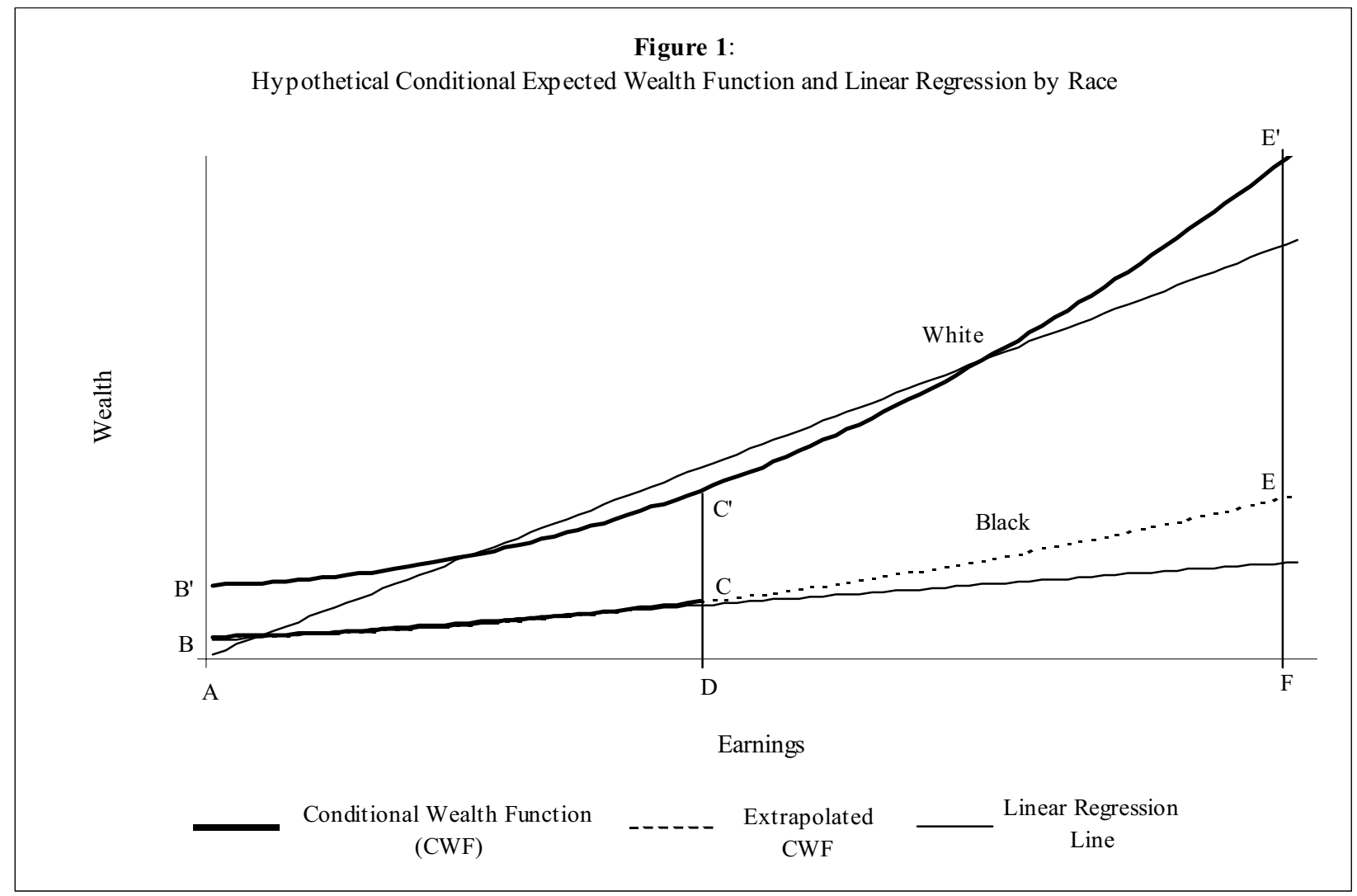


Figure 2:

Probability Distribution of Average Labor Earnings

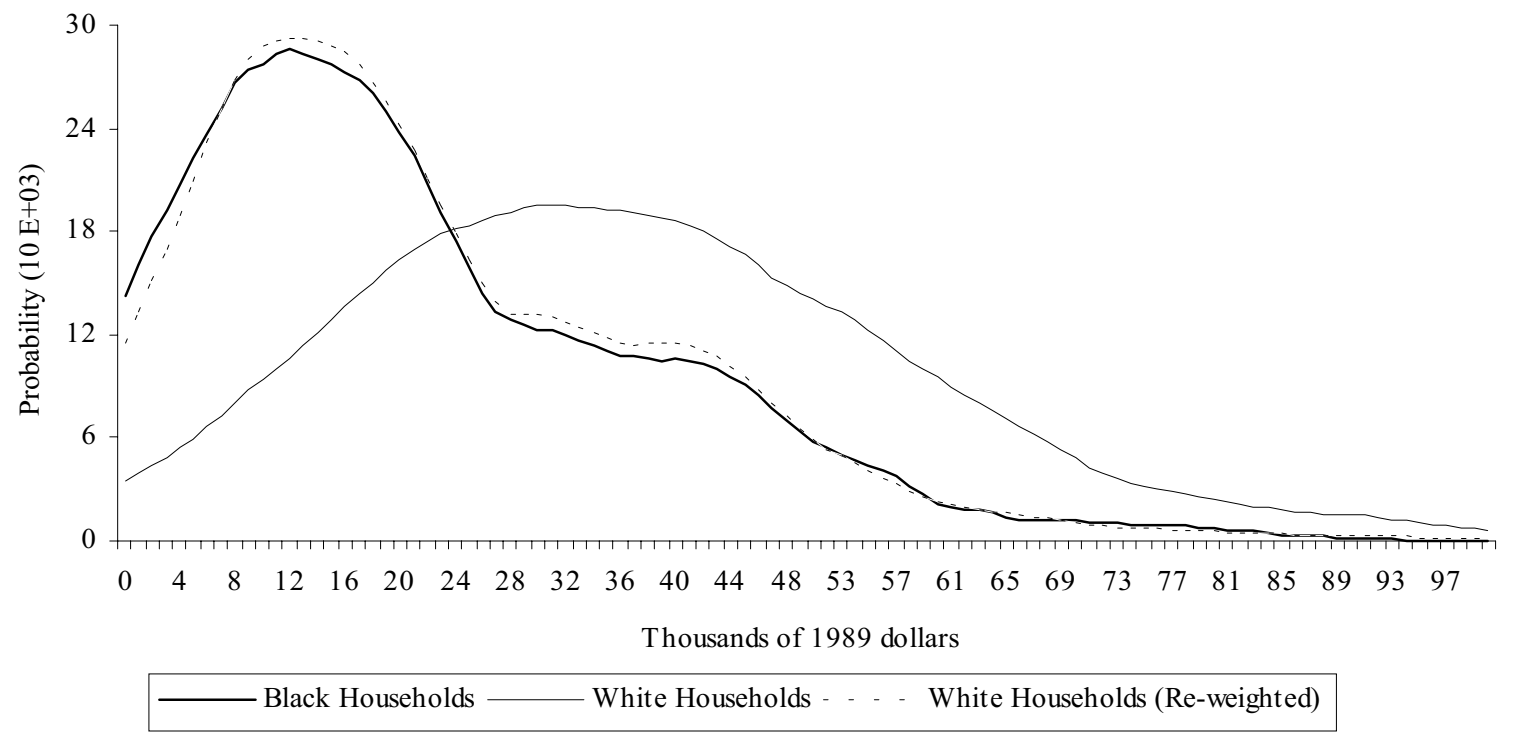

Note: Figure based on authors' calculations using the Panel Study of Income Dynamics. Sample is comprised of black and white household heads in 1984, 1989 or 1994 aged 45 to 49. Households were also required to have at least five years of observations prior to 1984, 1989 or 1994 (1,300 observations; 409 black and 891 white). PSID sample weights are used in all computations. The re-weighted white household earnings distribution is estimated using sample weights modified to match the white earnings distribution to the black distribution. The figure is truncated at $\$ 100,000$.

Figure 3:

Empirical Conditional Expected Wealth Functions by Race

(Thousands of 1989 dollars)

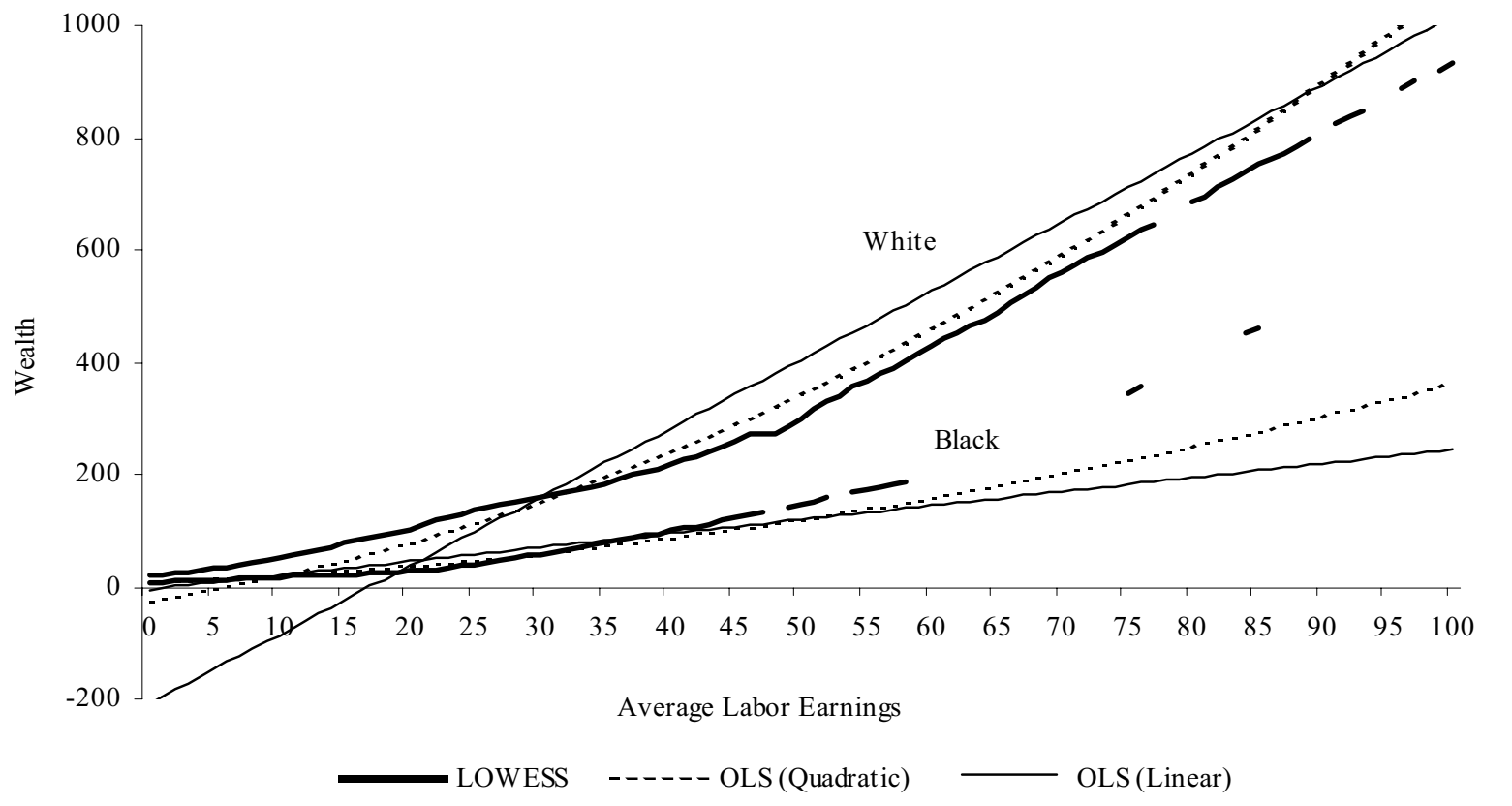

Note: Figure based on authors' calculations using the Panel Study of Income Dynamics. Sample is comprised of black and white household heads in 1984, 1989 or 1994 aged 45 to 49. Households were also required to have at least five years of observations prior to 1984, 1989 or 1994 (1,300 observations; 409 black and 891 white). 

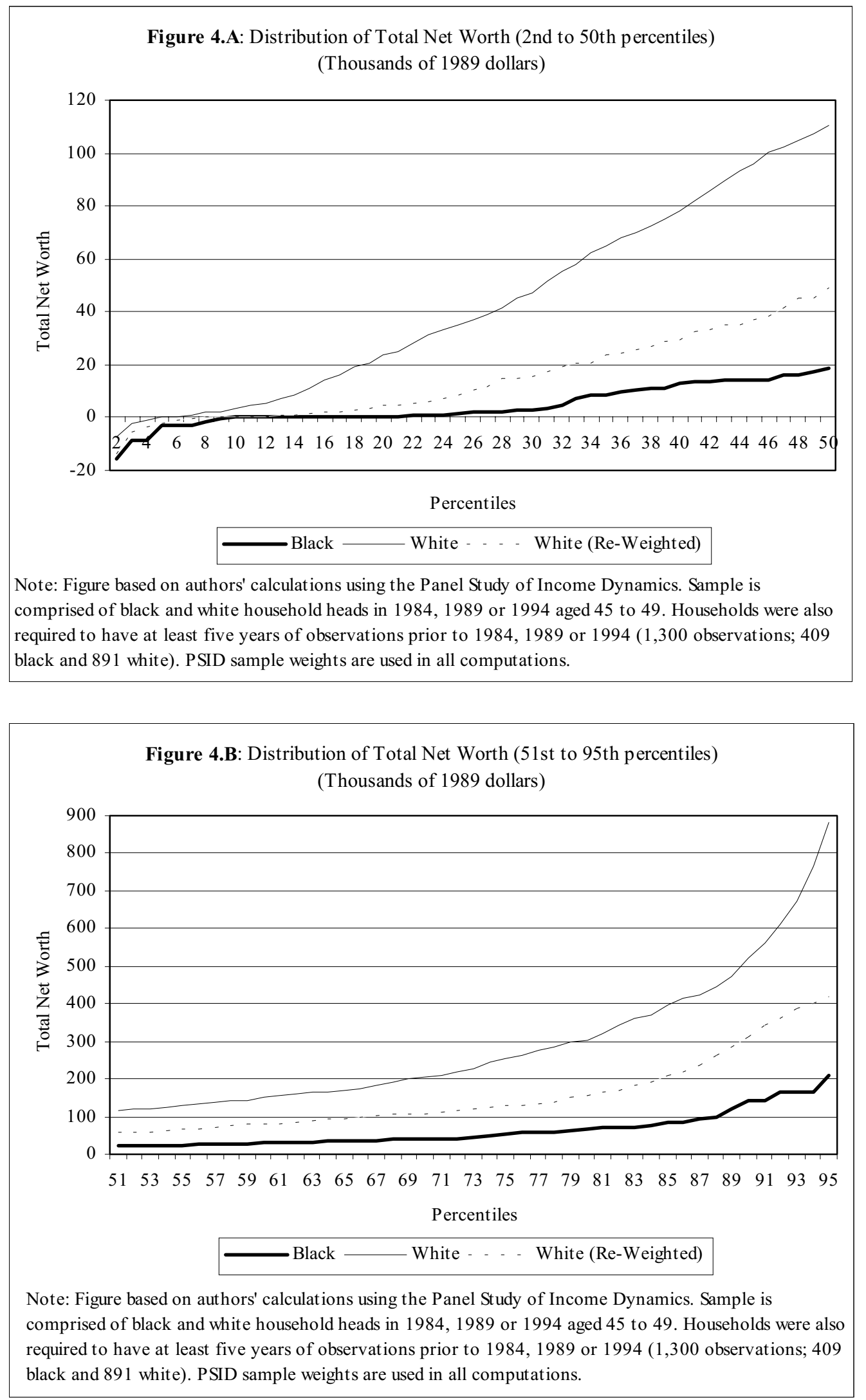